\title{
Fetal Heart Rate Pattern
}

National Cancer Institute

\section{Source}

National Cancer Institute. Fetal Heart Rate Pattern. NCI Thesaurus. Code C111774.

The sequence of a fetal heart rhythm and rate. 